\title{
SEX AND LIFE-HISTORY STAGE ALTER HERBIVORE RESPONSES TO A CHEMICALLY DEFENDED RED ALGA
}

\author{
Adriana Vergés, ${ }^{1,3,4}$ Nicholas A. Paul, ${ }^{2}$ and Peter D. Steinberg ${ }^{3}$ \\ ${ }^{1}$ Centre d'Estudis Avançats de Blanes CSIC, Accés a la Cala Sant Francesc 14, 17300 Blanes, Girona, Spain \\ ${ }^{2}$ School of Marine and Tropical Biology, James Cook University, Townsville 4811 Australia \\ ${ }^{3}$ School of Biological, Earth and Environmental Sciences, and Centre for Marine Bio-Innovation, \\ University of New South Wales, Sydney 2052 Australia
}

\begin{abstract}
Intraspecific variation in resistance to herbivory among genders and life-history phases of primary producers can significantly alter the ecological and evolutionary consequences of plant-herbivore interactions. Seaweeds (macroalgae) with complex life histories have multiple distinct phases with associated variation in traits that can potentially lead to differences in resistance to consumers and provide a unique system in which to simultaneously test the effects of sex and life-history stage on herbivory. We tested the susceptibility to grazing of the three life-history stages and separate sexes of the chemically defended red alga Asparagopsis armata against the sea hare Aplysia parvula, and we related this to the plant quality traits of different stages and genders. Differences in nutrient content and halogenated secondary metabolites between life-history phases were highly sex dependent. Male gametophytes had a low concentration of secondary metabolites and the highest nutrient content. The highest secondary metabolite content was found within the female gametophyte, in the wall of the reproductive structures (cystocarps) that contain the microscopic carposporophyte phase. Feeding choices by A. parvula were consistent with differences in algal quality and defense and resulted in the haploid male gametophytes being the most preferred food type. The diploid carposporophyte found inside the chemically rich cystocarps was the least consumed life-history stage. Selective herbivory of male gametophytes by $A$. parvula is consistent with an observed shift in gametophyte sex ratio in the field from unity at the beginning of the reproductive season to female bias at the end. The variation in susceptibility to herbivory found between sex and life-history stages of $A$. armata represents the first example of sex-biased consumption in seaweeds and may contribute to the maintenance of complex life histories such as those found in red algae.
\end{abstract}

Key words: algae; Aplysia parvula; Asparagopsis armata; chemical defense; dioecy; herbivory; heteromorphic life cycle; life history; plant-herbivore interaction.

\section{INTRODUCTION}

Resistance mechanisms are one of the main strategies of defense of plants against herbivory and are based on nutritional, chemical, or structural plant adaptations that lower plant quality and reduce herbivore preference or performance (Fritz and Simms 1992). Differences in such plant quality traits occur both between and within plant species and result in important variation in herbivore damage (Poore and Steinberg 1999, Marquis et al. 2001). Intraspecific variation in resistance to herbivory throughout the life history or individual development of plants can critically alter the ecological and evolutionary consequences of plant-herbivore interactions (Ehrlen 2002, Boege and Marquis 2005).

Manuscript received 13 February 2007; revised 19 September 2007; accepted 24 September 2007. Corresponding Editor: J. J. Stachowicz.

${ }^{4}$ Present address: Centre for Ecosystem Management, School of Natural Sciences, Edith Cowan University, 100 Joondalup Drive, Joondalup, WA 6027, Australia.

E-mail: a.verges@ecu.edu.au
However, ontogenetic changes in plant quality traits that confer resistance are also shaped by resource allocation constraints as well as demographic priorities such as establishment, growth, and reproduction (Pavia et al. 1999). These constraints imply tradeoffs between different tissues or organs and between different lifehistory stages in species with complex life cycles (Stearns 1992). While the general effect of plant quality and resistance traits on rates of herbivory are well known (Fritz and Simms 1992), much less is known about specific sources of intraspecific variation in susceptibility to grazing stemming from life-history parameters such as ploidy or gender (Cornelissen and Stiling 2005, Thornber et al. 2006).

Understanding the role of life-history traits for resistance is particularly challenging for organisms with complex life cycles, for which multiple distinct phases often differ in their functional characteristics (Podolsky and Moran 2006 and references therein). Recent evidence from marine invertebrates indicates that events in one life-history stage can have strong carryover effects on later stages (Gimenez 2004, Marshall and Keough 
2006). Similarly, in algae with complex life cycles, functional properties of one phase, such as resistance to herbivory, may also strongly impact other phases. This highlights the need to examine the life history of such organisms as a whole, rather than as a series of discrete units.

Many algae, fungi, mosses, and ferns have life cycles in which there is an alternation of generations between free-living haploid and diploid phases (Kirkpatrick 1994). One potential advantage of such diplohaplontic organisms is a more efficient exploitation of a broader range of environments by ecological differentiation of the two ploidy phases (Klinger 1993, Mable and Otto 1998, Hughes and Otto 1999). Haploid and diploid stages may differ in morphological (e.g., shape and size), physiological (e.g., productivity and growth), or demographic (e.g., recruitment and survival) properties (Zupan and West 1990, Martinez and Santelices 1998, Thornber and Gaines 2004). Such phase-specific differences can lead to variation in the resistance to herbivores, a selective process that may favor the maintenance of complex life histories (Klinger 1993). Life-history-stage grazing selectivity appears common among algae with heteromorphic life cycles (Lubchenco and Cubit 1980, Slocum 1980), but has also been described in a very few instances for species with morphologically indistinguishable life-history stages (Buschmann and Santelices 1987, Thornber et al. 2006).

Gender-specific differences in plant quality traits also result in biased herbivory (reviewed by Cornelissen and Stiling 2005) and may represent a driving force in the evolution and maintenance of dioecy (Bawa 1980, Ashman 2002). For dioecious plants, separate sexes differ in their morphological, physiological, and demographic traits (reviewed by Delph 1999). For instance, females tend to invest more energy into sexual reproduction and defense, while males invest more in vegetative growth (Delph 1999, Cornelissen and Stiling 2005). This variation in plant quality is a possible mechanism for differences in herbivory between sexes, and a recent meta-analysis on the effect of plant sex on plant-herbivore interactions showed a predominance of male-biased herbivory (Cornelissen and Stiling 2005 and references therein).

Although there has been recent interest on the effects of ploidy, life-history stage, and gender in susceptibility to herbivory (Cornelissen and Stiling 2005, Pearse et al. 2006, Thornber et al. 2006), very little is known about how these life-history parameters interact and affect plant-herbivore interactions. Seaweeds provide a unique system in which to simultaneously test the effects of sex, ploidy, and life-history stage on herbivory, since there are many dioecious species with complex life cycles that involve at least two free-living stages of differing ploidy (Klinger 1993 and references therein). Asparagopsis armata is a chemically defended dioecious red alga with a heteromorphic diplohaplontic life history (Bonin and Hawkes 1987). In this species, female and male haploid gametophytes coexist in space during part of the year with diploid sporophyte individuals. We tested the susceptibility to grazing of the different life-history stages and separate sexes of Asparagopsis armata against the sea hare Aplysia parvula, a known consumer of this species and a specialist feeder of chemically defended algae (Rogers et al. 2003, Paul et al. 2006a). We measured chemical and nutritional traits of the different algal parts offered to consumers in order to relate differences in herbivory to the quality traits of vegetative and reproductive tissues of different ploidy stages and genders. Since sex-biased herbivory was identified in our study, we monitored the adult gametophyte sex ratio of A. armata in the field to determine whether the observed herbivore selectivity might affect natural populations. Specifically, we asked (1) is there intraspecific variation in nitrogen content and secondary metabolite composition in A. armata? (2) Do separate genders or life-history stages differ in their susceptibility to herbivory by Aplysia parvula? If so, (3) what is the role of chemical defenses in determining these differences? And if sexbiased herbivory exists, (4) does the adult gametophyte sex ratio in the field reflect herbivore feeding preferences?

\section{Materials And Methods}

\section{Study organisms}

Asparagopsis armata (Harvey) has a triphasic heteromorphic life cycle typical of Florideophycean red algae (Fig. 1), alternating between a plumose gametophyte (haploid), a microscopic carposporophyte (diploid), and a filamentous tetrasporophyte (diploid), also known as the "Falkenbergia" stage. The gametophytes and tetrasporophytes (hereafter referred to as sporophytes) are macroscopic free-living stages. The carposporophyte is found inside the cystocarps, which are specialized reproductive structures found in the female gametophyte. A. armata is endemic to the southern hemisphere, and in its native range sporophytes are present throughout the year, while gametophytes are only present from August until December/January (Bonin and Hawkes 1987; A. Vergés, personal observation).

The sea hare Aplysia parvula (Guilding) Mörch is a cryptic herbivorous opisthobranch mollusk that commonly eats chemically defended red algae that are unpalatable to other herbivores (Rogers et al. 2003, Paul et al. 2006a). Asparagopsis armata is among the preferred diets for A. parvula (Rogers et al. 2003), and this sea hare was the only animal commonly found among the algae. A. parvula is characterized by important fluctuations in abundance with regularly occurring peaks, or booms, in sea hare populations during periods of only a few weeks (Rogers et al. 2003). A. parvula individuals used in experiments were collected from either A. armata, Delisea pulchra (Greville) Montagne, or Laurencia sp. around Bare Island, Sydney, Australia $\left(33^{\circ} 59^{\prime} \mathrm{S}, 151^{\circ} 13^{\prime} \mathrm{E}\right)$. 

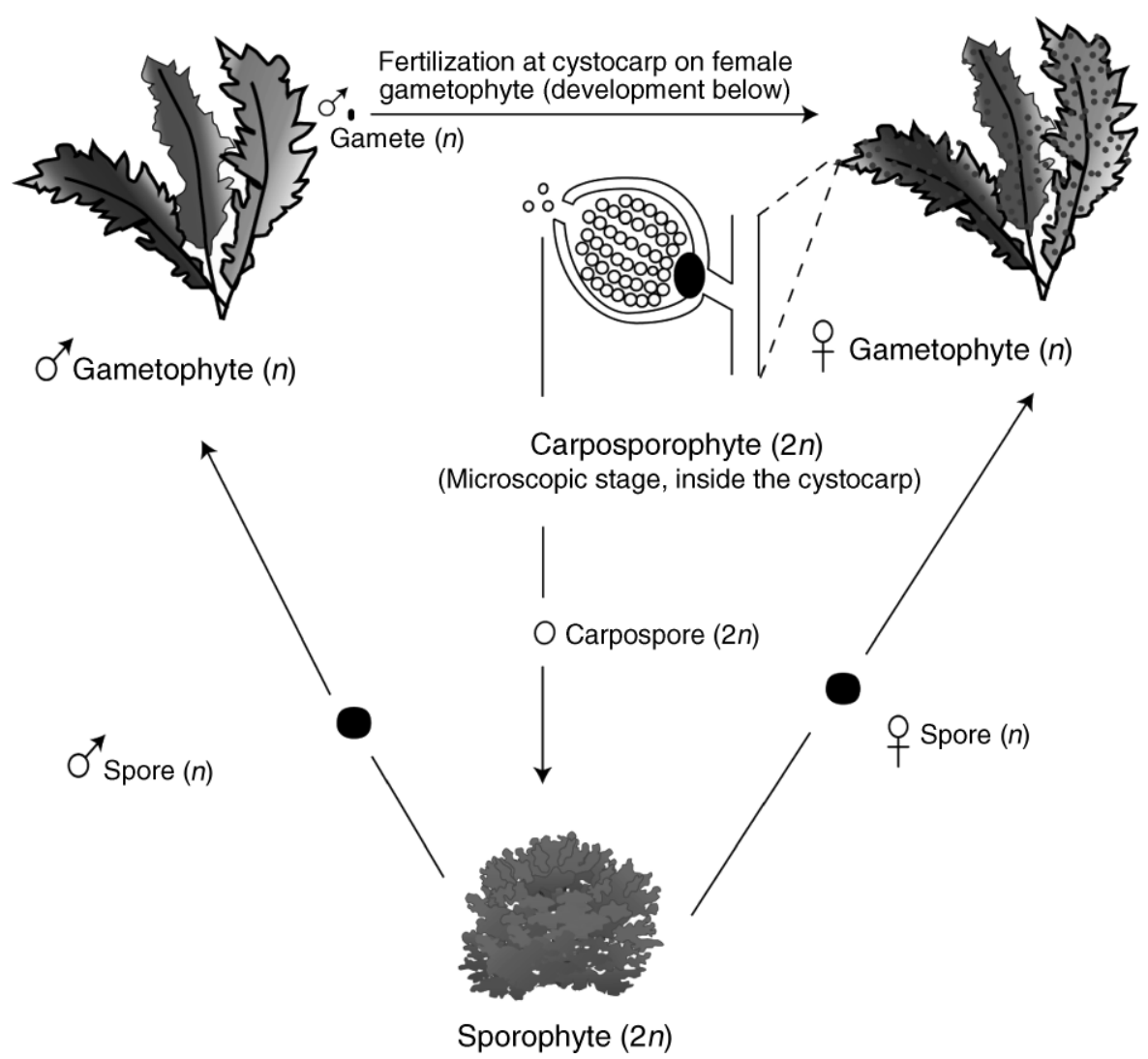

FIG. 1. Tri-phasic, diplohaplontic life history of Asparagopsis armata, typical of Florideophycean red algae. The free-living, filamentous diploid ( $2 n)$ sporophyte ("Falkenbergia" stage) produces haploid $(n)$ spores via meiosis, and these develop into male or female free-living plumose gametophytes. Haploid gametophytes produce male or female gametes. Fertilization occurs on the female reproductive structures or cystocarps and gives rise to a diploid zygote that develops into a multicellular carposporophyte that remains dependant to the female thallus. The microscopic carposporophyte produces diploid carpospores that are released in the water column and develop into sporophytes. Figure art is from Integration and Application Network (University of Maryland Center for Environmental Science, Cambridge, Maryland, USA 〈http://ian.umces.edu/symbols $\rangle$ ).

\section{Feeding preference assays with living algae}

Feeding assays were run in a constant-temperature room kept at $19^{\circ} \mathrm{C}$. Before every feeding assay, all animals were acclimatized to laboratory conditions over a $24-48 \mathrm{~h}$ period during which they were fed freshly collected Ulva sp. In all assays, a single sea hare was placed in individual compartments that were aerated and separated from larger tanks of seawater or other compartments by $300-\mu \mathrm{m}$ mesh. We began all feeding assays with 15-30 replicates, but the final numbers varied for each assay, as replicates where herbivores failed to feed were discarded. Algae were blotted dry of excess water prior to measuring the initial and final wet masses. We used an equal number of no-herbivore controls for each experiment. All algal material was collected and transported to the laboratory a few hours prior to assays. As gametophytes of Asparagopsis armata from the field do not survive for very long after being cut into smaller pieces, all assays were stopped after $24 \mathrm{~h}$ if measurable amounts of biomass had been consumed, with a maximum of a 48-h assay.
We first quantified the feeding preferences between male and female gametophytes. This was done as a series of paired-choice feeding assays where we simultaneously offered living apical pieces of equivalent masses of randomly collected male and female gametophyte specimens bearing either reproductive spermatia or cystocarps. We then performed additional assays on feeding preferences between (1) sporophytes and female gametophytes and (2) sporophytes and male gametophytes. Finally, in order to quantify any preferences by $A$. parvula between vegetative parts of the female gametophyte (i.e., branches) and reproductive structures (i.e., cystocarps, which contain the microscopic carposporophyte stage; Fig. 1), we ran a multiple-choice feeding assay. We offered each $A$. parvula individual a gametophyte fragment $(\sim 1 \mathrm{~cm}$ length) bearing cystocarps. These were photographed before and after herbivore feeding using a Sony DFW Digital microscope-coupled camera (Sony, New York, New York, USA). The areas consumed of individual algal parts (branches, main axis, and cystocarps) were measured 
using ImageJ image analysis software (available online). ${ }^{5}$ Autogenic changes in the area of controls were negligible relative to changes in area due to consumption, and these were thus not included in the analysis.

\section{Chemical analyses of Asparagopsis armata}

The chemistry of Asparagopsis armata is well characterized, with over 100 halogenated compounds having been found (McConnell and Fenical 1977). The major halogenated metabolite of A. armata in Sydney populations is bromoform (ranging from $0.66 \%$ to $4.35 \%$ dry mass $(\mathrm{DM})$; mean $\pm \mathrm{SE}$ of $1.67 \% \pm 0.16 \% \mathrm{DM})$, followed by dibromoacetic acid (DBA; ranging from $0.02 \%$ to $2.6 \% \mathrm{DM} ; 0.74 \% \pm 0.16 \%$ ), dibromochloromethane $(0.02 \% \pm 0.002 \%)$, and bromochloroacetic acid $(0.25 \% \pm 0.06 \%$; see Paul et al. 2006b). The concentrations of the major metabolites are strongly correlated (e.g., $\mathrm{CHBr}_{3}$ vs. DBA; $r=0.995, P<0.001$; Paul et al. $2006 b$ ). Consequently, we used the major metabolite (by mass) bromoform, $\mathrm{CHBr}_{3}{ }^{-}$, as an indicator for total halogenated metabolite concentration.

For each life-history stage or algal part, we quantified bromoform content and nitrogen composition to assess whether these variables correlated with herbivore feeding preferences. All samples used for chemical analysis were subsamples from the algae used in the feeding assays; i.e., they were collected on the same date and from the same population. Total nitrogen content was analyzed on algal freeze-dried material using a Carlo-Erba elemental autoanalyser (EA-1110 CHN-O; Milan, Italy). Bromoform was quantified using gas chromatography-mass spectrometry (GC-MS; Hewlet Packard 5890 series II gas chromatograph, Palo Alto, California, USA) as per Paul et al. (2006b). The ion fragments characteristic of bromoform were the molecular ion cluster at $\mathrm{m} / \mathrm{e} 250,252,254,256$ [1:2:2:1], and $\mathrm{M}+-173$. Samples were freeze-dried, weighed, and extracted in $100 \%$ methanol using $10 \mu \mathrm{g} / \mathrm{mL}$ naphthalene as an internal standard. The extraction volume used was approximately $30 \mu \mathrm{L}$ methanol $/ \mathrm{mg}$ algal DM. We extracted the algal samples in methanol inside the GCMS vials, which were sealed and sonicated for 15 minutes. Bromoform was quantified after extracting for $72 \mathrm{~h}$ at $-30^{\circ} \mathrm{C}$.

\section{Role of secondary metabolites in determining the feeding preferences of $\mathrm{A}$. parvula}

Since Aplysia parvula showed a feeding preference toward algae with lower bromoform concentrations (see Results), we tested the role of secondary metabolites in determining the sea hare's feeding choices. Preliminary trials by us and by Rogers (2000) showed that $A$. parvula does not feed on agar or carrageen-based artificial diets, and we therefore used blades of Ulva sp. coated with pure metabolites instead, a method often used to detect

\footnotetext{
${ }^{5}\langle$ http://rsb.info.nih.gov/ij $\rangle$
}

chemical deterrence against herbivores (e.g., Hay et al. 1998). We tested the combined effect of the two main metabolites of Asparagopsis armata, bromoform, and DBA (Paul et al. 2006b). There are also other halogenated metabolites in A. armata, such as bromochloroacetic acid and dibromochloromethane (McConnell and Fenical 1977) that may also impact $A$. parvula feeding behavior, but these are found at much lower levels than DBA and bromoform in the alga, and we were unable to incorporate them into these diets due to logistic constraints. In paired feeding-preference assays, each sea hare was offered a choice between control Ulva discs containing no metabolites and treatment Ulva discs containing bromoform and DBA at one time and two times the cystocarp wall concentration (2\% dry mass bromoform, $0.57 \%$ DM DBA). Further attempts to run choice experiments at higher metabolite concentrations failed, as the sea hares did not eat either control or treatment discs, suggesting a complete feeding deterrence due to metabolites leaching into the water.

Ulva discs were cored from fresh samples $\left(2 \mathrm{~cm}^{2}\right)$, spread out, and air dried prior to applying compounds. Both DBA and bromoform were dissolved in diethyl ether (DEE) and added to the surface of the alga to give the same dry-mass concentration as the algal diets. The ether evaporates within a few seconds, leaving the metabolites adhered to the surface of the Ulva sp. core (Hay and Fenical 1988). Each side of the Ulva disc was coated with an equal amount of DEE (treatment and control alike). Treatment and control discs were marked by threading different colored cotton through the centre of each disc. As Ulva sp. is uniformly two cells thick, consumption was measured by the size (area) of the feeding scar, which was always at the edge of the disc. As preliminary tests determined that the area of excised discs did not change overnight, consumption was measured as a loss of area from the initial $2-\mathrm{cm}^{2}$ digital images pre- and post-consumption.

\section{Sex ratio}

We measured the sex ratio of Asparagopsis armata populations over time by randomly collecting lateral branches from 50 to 75 gametophytes and identifying either macroscopic cystocarps in females or microscopic spermatia in males. Sex ratio was monitored every two weeks during three months (September-November 2006) at Bare Island (Sydney, Australia). Additionally, gametophyte sex ratio was measured once at the end of the algal reproductive period on three populations from eastern Australia. We sampled $A$. armata populations at Bare Island during two consecutive seasons in late November of 2004 and 2005, and a population from Ulladulla $\left(35^{\circ} 22^{\prime} \mathrm{S}, 150^{\circ} 29^{\prime} \mathrm{E}\right)$ during December 2005.

\section{Statistical analyses}

Differences in feeding in paired preference assays were analyzed using $t$ tests as per the approach outlined by Peterson and Renaud (1989). The $t$ statistic was 

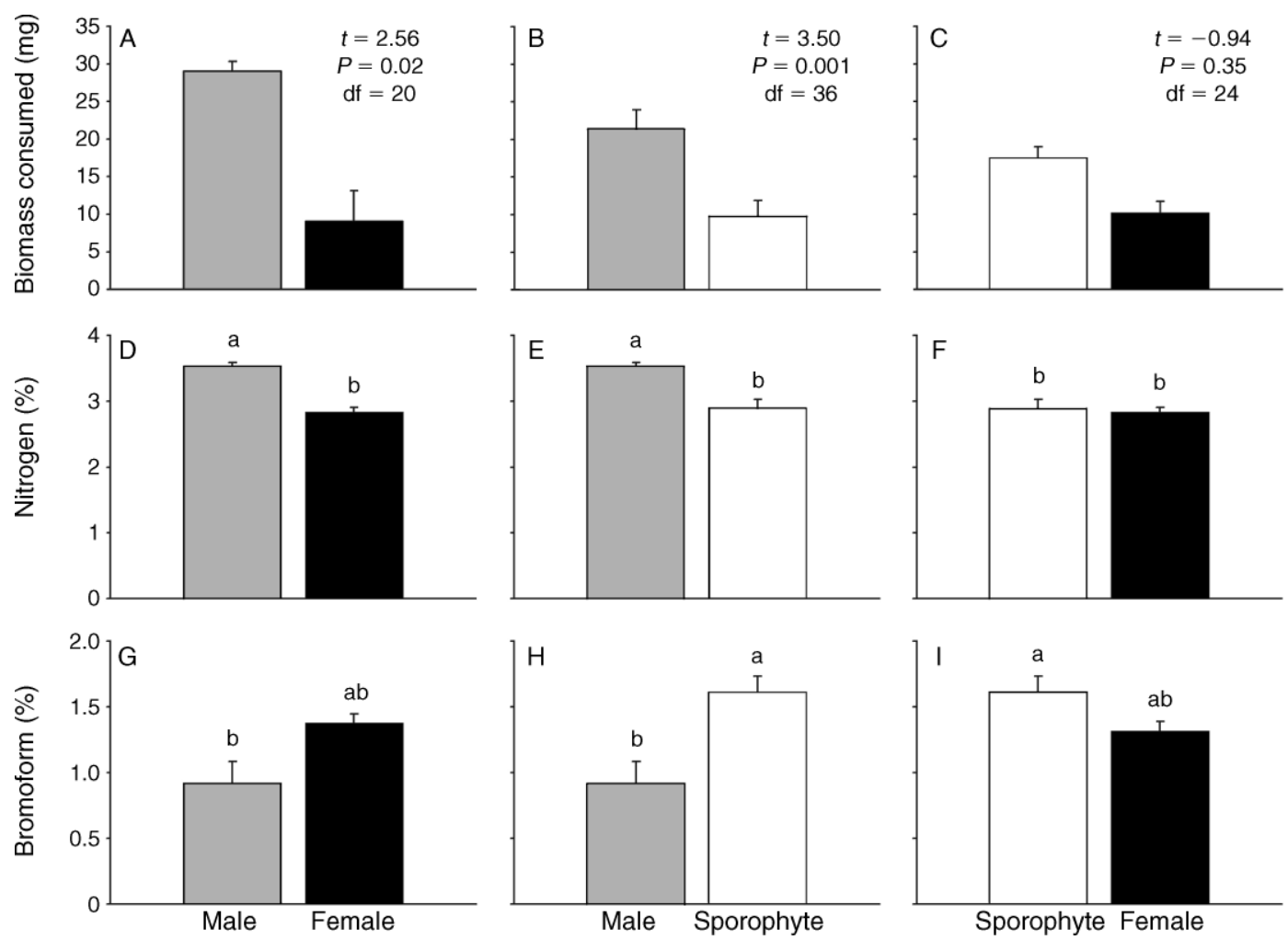

FIG. 2. (A-C) Sex and life-history stage feeding preferences of the sea hare Aplysia parvula. (D-F) Nitrogen and (G-I) bromoform concentration of the different algal genders and stages $(N=5$ thalli). Bars show mean biomass consumed/concentration values and SE. Values in bold indicate significant feeding preferences at $P<0.05$. Probability values in A-C were generated by $t$ tests. Bars sharing the same letter do not differ significantly at $P>0.05$ (Tukey's hsd).

calculated by comparing the between-food differences in mass/area change of treatment replicates (choice 1 choice 2, with herbivores) to control replicates (choice 1 - choice 2, without herbivores). Consumption rates measured as wet biomass were low relative to autogenic changes in control, and we therefore set a minimum value for consumption of at least $1 \mathrm{SD}$ of the mean change in biomass of the autogenic controls. This ensured that only those replicates where feeding had definitely occurred were included in the analyses. Differences in chemical composition between life-history stages and genders (sporophytes, male and female gametophytes), and between the different parts of the female gametophytes were analyzed using one-way ANOVAs. Differences in feeding from the multiplechoice female gametophyte experiment were analyzed using proportional consumption data and Hotelling's multivariate $T^{2}$ test as modified by Lockwood (1998). Adult sex ratio was analyzed using a likelihood ratio goodness-of-fit test ( $G$ test) comparing our observed numbers of males and females with the numbers expected under an equal sex ratio. All data were checked for normality and equality of variances by visual inspection of scatterplots and distribution of residuals (Quinn and Keough 2002).

\section{RESUlts}

\section{Intraspecific feeding preferences and chemical content}

The sea hare, Aplysia parvula, showed a strong preference for male gametophytes, consuming over three times more male than female gametophytes (Fig. 2A) and two times more male gametophytes than sporophytes (Fig. 2B). In contrast, the sea hare did not distinguish between female gametophytes and sporophytes (Fig. 2C). The feeding preferences of $A$. parvula were consistent with differences in plant quality, since the sea hare generally preferred algal phases with the highest nitrogen content and lowest bromoform levels. One-way ANOVA on the chemical composition of sporophytes, male and female gametophytes showed significant differences in both nitrogen content $\left(F_{2,12}=\right.$ 18.08, $P<0.001$; Fig. 2D-F) and bromoform concentration $\left(F_{2,12}=7.94, P=0.006\right.$; Fig. 2G-I $)$. Male gametophytes had higher nitrogen content (Fig. 2E) and lower bromoform levels (Fig. 2H) than sporophytes (Tukey hsd $P \leq 0.01$ for all comparisons). Similarly, male gametophytes also had higher nitrogen content than female gametophytes (Fig. 2D; Tukey's hsd $P<$ 0.001 ) and a near-significantly higher bromoform concentration (Fig. 2G; Tukey hsd $P=0.059$ ). In contrast, female gametophytes did not differ significant- 


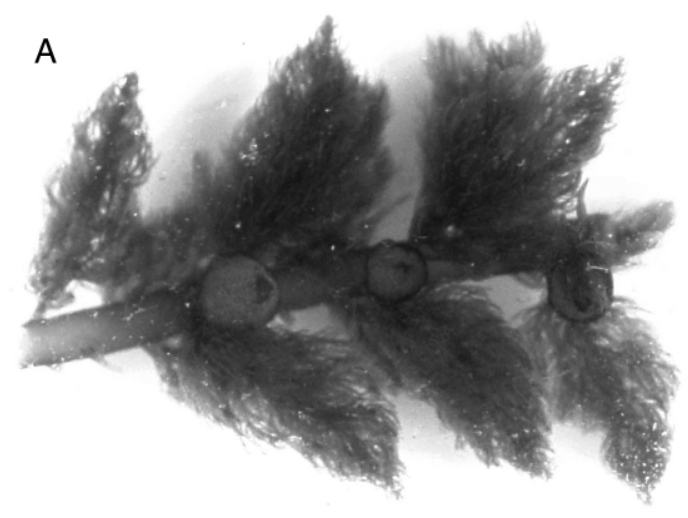

B

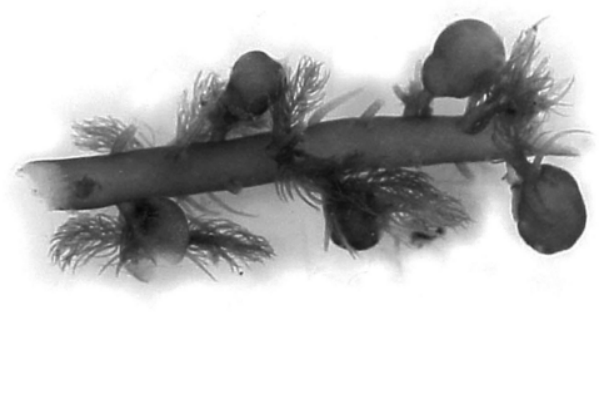

FIG. 3. Photographs of the Asparagopsis armata female gametophyte piece offered to each Aplysia parvula individual during the multiple choice feeding experiment at (A) the beginning of the assay and (B) after feeding had occurred. Round cystocarps are approximately $3 \mathrm{~mm}^{2}$. Photo credits: N. Paul and A. Vergés.

ly from sporophytes in either nitrogen or bromoform content (Fig. 2F, I).

When offered a section of the female gametophyte, Aplysia parvula clearly distinguished between algal parts, preferring to eat branches over either cystocarps or the main axis (Figs. 3 and $4 \mathrm{~A}$; critical $F_{2,17}=7.80$, Hotelling's $T^{2}=3879.9, P<0.001$; Lockwood 1998). Although availability differed among algal parts (area of branches was six times larger than either cystocarps or main axis), this is not what led to differential consumption, as we obtained similarly strong results when data were analyzed as percentage consumed of each food type relative to the initial area of each food type (for percentage consumed \pm SE, branches $=46.22 \% \pm$ $6.73 \%$; cystocarps $=16.66 \% \pm 5.55 \%$; main axis $=$ $22.86 \% \pm 5.58 \%)$. There were also significant differences in nitrogen content within the female gametophyte $\left(F_{2,10}\right.$ $=17.53, P<0.001$; Fig. 4B). Again, the preferred vegetative branches were richest in nitrogen, with a higher concentration than either the cystocarps or the main axes (Tukey's hsd, $P \leq 0.001$ for both comparisons). Nitrogen concentration of the cystocarps wall or the carposporophyte could not be determined due to insufficient mass of samples. There were also significant differences in bromoform concentration within the female gametophyte $\left(F_{4,18}=108.8, P<0.0001\right.$; Fig. $4 \mathrm{C}$ ). The carposporophyte (the life-history stage contained within the cystocarp) had the lowest bromoform concentration (almost undetectable), whereas the cystocarp wall (protecting the carposporophyte) had the highest (Fig. 4C; Tukey's hsd test, $P<0.0001$ for all comparisons except $P=0.014$ for between cystocarp wall with branches). Female branches had the second highest bromoform levels (Tukey's hsd test, $P \leq 0.001$ for all comparisons except with cystocarp wall), whereas the main axis and the cystocarps as a whole (i.e., combined components of wall and carposporophyte) had similar intermediate values.
Role of secondary metabolites in determining the feeding preferences of Aplysia parvula

When we offered the sea hare Aplysia parvula a choice between control and treatment Ulva discs coated with bromoform and dibromoacetic acid at the mean cystocarp wall concentration, we found a near-significant deterrence of the secondary metabolites $(t=1.77$, $\mathrm{df}=21, P=0.091$; mean area consumed $\pm \mathrm{SE}, 1.59 \pm$ $0.25 \mathrm{~cm}^{2}$ for control discs and $1.03 \pm 0.21 \mathrm{~cm}^{2}$ for treatment discs). A total of 22 out of 29 sea hares (76\%) consumed at least some of one diet choice in this assay. We found a stronger trend toward a feeding preference for control discs over treatment discs coated with metabolites at two times the cystocarp wall concentration $(t=2.287, \mathrm{df}=7, P=0.056$; mean area consumed \pm SE, $1.32 \pm 0.29 \mathrm{~cm}^{2}$ for control discs and $0.25 \pm 0.22$ $\mathrm{cm}^{2}$ for treatment discs). However, only 8 out of 15 individuals (53\%) fed upon control and/or treatment foods in this assay. This reduction in the number of feeding individuals, combined with additional trials with higher metabolite concentrations (five-times cystocarp wall concentration) that resulted in no feeding, suggests that leaching of metabolites occurred in the assays. However this did not seem to influence those sea hares that did feed (i.e., those used in the analyses), as there was no obvious change in the overall amount consumed of the controls between assays (mean area consumed \pm SE, $1.59 \pm 0.25 \mathrm{~cm}^{2}$ for one-times-concentration assay and $1.32 \pm 0.29 \mathrm{~cm}^{2}$ for the two-times-concentration assay). If leaching did occur, then the actual metabolite concentration was unavoidably lower than intended, making the one-times and two-times concentration feeding results somewhat conservative. Additionally, the fact that we only incorporated the two main metabolites in our chemical assays (bromoform and DBA) adds to the conservative nature of our results since other minor metabolites such as bromochloro- 
acetic acid and dibromochloromethane may also add to a deterrent effect.

\section{Sex ratio}

At the beginning of the reproductive period (September), there were as many male as female Asparagopsis armata gametophytes in the field (Fig. 5; $G=1.286, P=$ $0.257)$. This equal sex ratio was maintained for over a month until the beginning of November, when the sex ratio became female-biased (Fig. 5; $G=12.199, P=$ $0.0001)$. The adult sex ratio of all populations toward the end of the gametophyte reproductive period was significantly female-biased in all instances (Table 1).

\section{Discussion}

This study demonstrates important differences in resistance to herbivory and algal quality between the genders and life-history stages of the chemically defended red seaweed Asparagopsis armata. Feeding preferences by the sea hare Aplysia parvula were chemically mediated and resulted in the haploid male gametophytes being the most preferred food type. In contrast, the diploid carposporophyte found inside specialized female reproductive structures was the least consumed life-history stage. This selective herbivory toward male gametophytes is consistent with a shift in gametophyte sex ratio observed in the field, from unity at the beginning of the reproductive season to female skewed toward the end.

Aplysia parvula is a specialist consumer of chemically defended algae that is known to consume $A$. armata preferentially (Rogers et al. 2003). A previous study has shown that this sea hare is not deterred by mean halogenated metabolite concentrations in $A$. armata sporophytes (Paul et al. 2006a). However, our results suggest that higher concentrations of the two main metabolites of the alga (bromoform and DBA) in specific parts of the gametophyte can deter this herbivore. Similarly, Ginsburg and Paul (2001) showed that $A$. parvula preferentially feeds on seaweeds that contain secondary metabolites at relatively low concentrations, but is deterred by high concentrations of these same compounds (Ginsburg and Paul 2001). In fact, chemical defenses of marine algae are often concentration dependent, with feeding deterrence occurring above a certain threshold value (Steinberg 1988, Bargu et al. 2006). In the multiple-choice feeding assay with the female gametophyte, A. parvula preferred the more nutritious lateral branches to the main axis or the reproductive cystocarps. It is likely that this preference was mediated by both the high bromoform concentration of the cystocarp wall and the higher nitrogen concentration of the branches. However, the higher visibility of these branches (i.e., branches surround the main axis and cystocarps are nestled amongst branches) may also make them more accessible.

To our knowledge, this is the first study to document gender-specific differences in susceptibility to herbivory
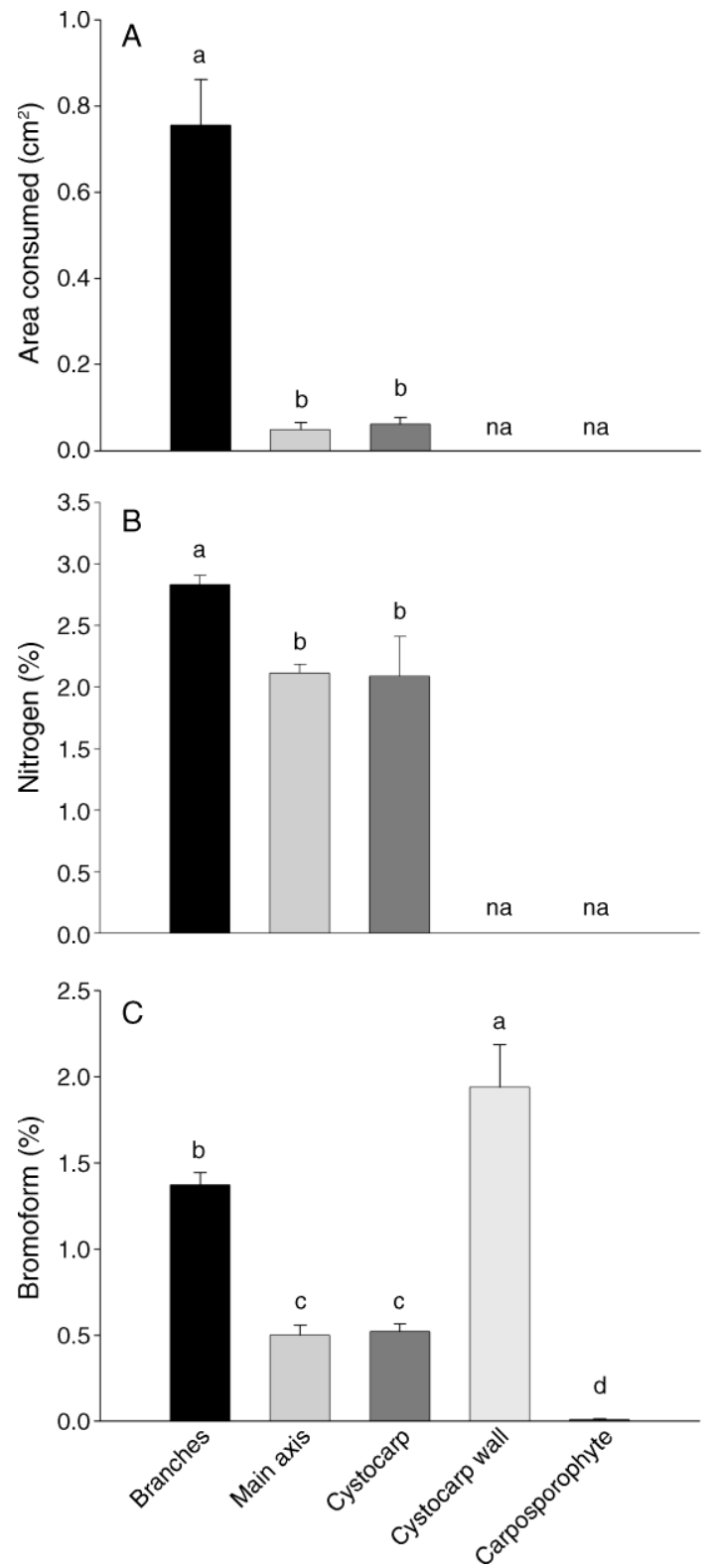

FIG. 4. (A) Within-female gametophyte multiple-choice feeding preferences of Aplysia parvula. Bars show mean biomass consumed/concentration values and SE. Sample size was as follows: branches $(N=5)$, main axis $(N=5)$, cystocarps, measuring nitrogen and bromoform $\left(N_{\mathrm{N}}=2, N_{\mathrm{br}}=5\right)$, and bromoform-only concentration of cystocarp wall $(N=4)$ and carposporophyte $(N=4)$. Nitrogen content of the cystocarp wall and the carposporophyte could not be determined due to insufficient mass of samples (denoted as "na"). (B) Nitrogen concentration (percentage dry mass) of the branches, main axis, and cystocarps within the female gametophyte. (C) Bromoform concentration (percentage dry mass) of the different algal parts within the female gametophyte. Bars sharing the same letter do not differ significantly at $P>0.05$. In panel (A), multiple post hoc comparisons between differences in area consumed were analyzed as per Lockwood (1988). Tukey's hsd post hoc test was used for the multiple comparisons between algal parts of (B) nitrogen and (C) bromoform concentration. 


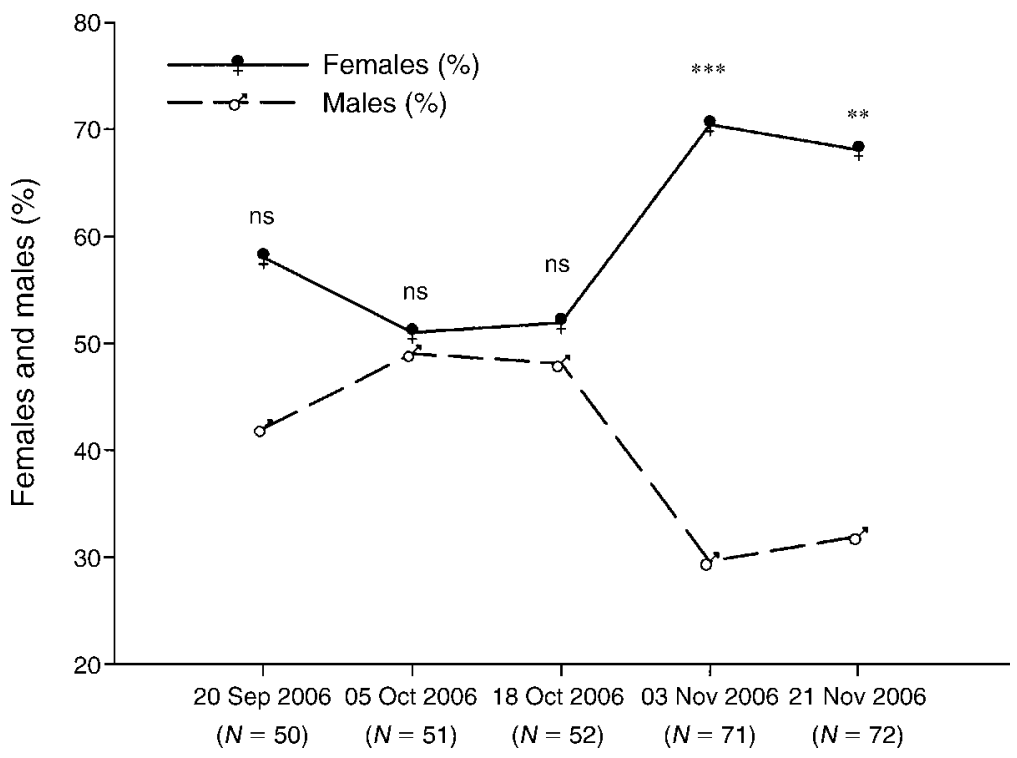

FIG. 5. Sex ratio of an Asparagopsis armata population from Bare Island (Sydney, Australia) during three months. Values in parentheses correspond to sample size. Probability values were generated by $G$ test values from one-way contingency analyses on the number of males and females for each date.

${ }^{*} P<0.05 ;{ }^{*} P<0.01 ;{ }^{* *} P<0.001$; ns, not significant.

in algae. Female gametophytes of Asparagopsis armata were a less preferred food source and had a nearsignificantly higher secondary metabolite concentration than males. This is consistent with a recent metaanalysis from terrestrial ecosystems that shows that female plants suffer less herbivory than males and are better defended in terms of secondary chemistry and other structural defenses (Cornelissen and Stiling 2005). Female plants usually invest more resources into reproduction and less into growth than males because they have to produce both flowers and fruits (Delph 1999). Similarly, female gametophytes of florideophycean algae such as Asparagopsis armata allocate energy to both gamete production and the development of the carposporophyte life-history stage; the latter remains connected to the female thallus and acquires nutrients from it continuously until spore discharge (Kamiya and Kawai 2002). Female gametophytes thus allocate resources to reproductive function for a longer period than males. Furthermore, sex-ratio monitoring indicated that female $A$. armata persist in the field longer than

TABLE 1. Adult sex ratio of Asparagopsis armata populations at the end of their reproductive period.

\begin{tabular}{lccrr}
\hline \hline \multicolumn{1}{c}{ Location and date } & $N$ & $\begin{array}{c}\text { Proportion } \\
\text { female }\end{array}$ & \multicolumn{1}{c}{$G$} & \multicolumn{1}{c}{$P$} \\
\hline Bare Island, November 2004 & 51 & 0.65 & 4.48 & 0.034 \\
Bare Island, November 2005 & 43 & 0.88 & 28.70 & $<0.001$ \\
Ulladulla, November 2005 & 49 & 0.78 & 14.74 & $<0.001$
\end{tabular}

Notes: $G$ test values are from one-way contingency analyses on the number of males and females on each population. $N=$ number of individuals. males. This increased longevity of females may lead to slightly higher levels of defense because of the relatively higher cost of losses to herbivory for slow growers (Coley et al. 1985, Jing and Coley 1990).

Optimal defense theory (ODT) predicts that tissues that contribute more to plant fitness or are more prone to predation should be better defended (McKey 1979, Rhoades 1979). Since female gametophytes contain an additional life-history stage within their specialized reproductive structures or cystocarps, this gender should be under strong selection to allocate resources to the protection of these particular parts against herbivory. Indeed, we found the highest levels of secondary metabolites in the cystocarp walls of female gametophytes, and these were a less preferred algal part by the sea hare Aplysia parvula. The high chemical defenses of the cystocarps wall are in stark contrast with the undetectable levels of secondary metabolites in the carposporophyte itself. This life-history stage thus appears to be dependent on the maternal gametophyte for both nutrition and protection against herbivores. Although nurture and protection of embryos by females are well known for placental mammals, the presence of a dependent embryonic stage among plants and algae is a unique feature of embryophytes (commonly referred to as land plants) and florideophycean red algae (Graham and Wilcox 2000). However, the maternal protection against herbivory of the carposporophyte stage found in A. armata does not appear to be a generalized trait of florideophycean red algae. Indeed, several authors have detected the exact opposite effect, with herbivores selectively feeding on reproductive cystocarps over other algal parts (Gaines 1985, Buschmann and Santelices 
1987, Thornber et al. 2006). Some authors have argued that amphipods that preferentially feed on cystocarps may be facilitating carpospore release and dispersion (Buschmann and Santelices 1987), thus suggesting a contrasting evolutionary role of herbivores on algal lifehistory dynamics to that described in the present study.

We have provided strong evidence for selectivity by a specialist herbivore between genders and life-history stages of an alga with a complex life history, and these differences are consistent with intraspecific differences in algal quality and chemical defenses. Such differences in susceptibility to herbivory may contribute to the maintenance of haplodiploid dioecious life histories. Although our understanding of the role of herbivores in the evolution of sexual systems is still in its infancy, recent studies have shown how male-biased herbivory may influence the evolution of separate sexes (Ashman 2002, Ashman et al. 2004, Ashman and Penet 2007). For instance, herbivory can select for separate sexes if it depresses female fertility but it does not lower male fertility (Bawa 1980, Ashman 2002). Moreover, although male plants may suffer higher levels of damage, their overall decline in fitness may be less than for females when male plants are expendable after gametes are dispersed (Bawa 1980), as seems to occur with Asparagopsis armata. Similarly, herbivory can strongly influence the mortality or fecundity of different algal life-history stages if these vary in their susceptibility to grazers, and recent studies show that the stability of haplodiploid life cycles can be promoted by such differences in demographic parameters, which need only be slight (Hughes and Otto 1999). We also present circumstantial evidence that selective herbivory may influence the sex ratio of $A$. armata gametophytes in the field. However, whether this biotic interaction exclusively dictates the observed sex ratio remains to be tested, as differences in demographic parameters such as longevity of the different genders or other mechanisms such as differential resistance to fouling organisms or pathogens between genders may also have an effect (Ågren et al. 1999).

\section{ACKNOWLEDGMENTS}

We thank students and staff from the Centre for Marine Biofouling and Bioinnovation (UNSW) for their help with fieldwork, S. Wood from the Australian National University for the carbon and nitrogen measures, and O. Roch of the University of Barcelona for providing statistical advice. Two anonymous reviewers provided thorough and instructive comments on the manuscript. This work was partially supported by an FPI Postgraduate Award to A. Vergés from the Spanish Ministry of Science and Education (REN-200204020-C02) and the Centre for Marine Bio-Innovation.

\section{Literature Cited}

Ågren, J., K. Danell, T. Elmqvist, L. Ericson, and J. Hjältén. 1999. Sexual dimorphism and biotic interactions. Pages $217-$ 246 in M. A. Geber, T. E. Dawson, and L. F. Delph, editors. Gender and sexual dimorphism in flowering plants. SpringerVerlag, Berlin Heidelberg.
Ashman, T. L. 2002. The role of herbivores in the evolution of separate sexes from hermaphroditism. Ecology 83:11751184.

Ashman, T. L., D. H. Cole, and M. Bradburn. 2004. Sexdifferential resistance and tolerance to herbivory in a gynodioecious wild strawberry. Ecology 85:2550-2559.

Ashman, T. L., and L. Penet. 2007. Direct and indirect effects of a sex-biased antagonist on male and female fertility: consequences for reproductive trait evolution in a genderdimorphic plant. American Naturalist 169:595-608.

Bargu, S., K. Lefebvre, and M. W. Silver. 2006. Effect of dissolved domoic acid on the grazing rate of krill Euphausia pacifica. Marine Ecology Progress Series 312:169-175.

Bawa, K. S. 1980. Evolution of dioecy in flowering plants. Annual Review of Ecology and Systematics 11:15-39.

Boege, K., and R. J. Marquis. 2005. Facing herbivory as you grow up: the ontogeny of resistance in plants. Trends in Ecology and Evolution 20:441-448.

Bonin, D. R., and M. W. Hawkes. 1987. Systematics and life histories of New Zealand Bonnemaisoniaceae (Bonnemaisoniales, Rhodophyta). 1. The Genus Asparagopsis. New Zealand Journal of Botany 25:577-590.

Buschmann, A., and B. Santelices. 1987. Micrograzers and spore release in Iridaea laminarioides Bory (Rhodophyta, Gigartinales). Journal of Experimental Marine Biology and Ecology 108:171-179.

Coley, P., J. Bryant, and F. Chapin, III. 1985. Resource availability and plant antiherbivore defense. Science 230:895899.

Cornelissen, T., and P. Stiling. 2005. Sex-biased herbivory: a meta-analysis of the effects of gender on plant-herbivore interactions. Oikos 111:488-500.

Delph, L. F. 1999. Sexual dimorphism in life history. Pages 149-173 in M. A. Geber, T. E. Dawson, and L. F. Delph, editors. Gender and sexual dimorphism in flowering plants. Springer-Verlag, Berlin, Germany.

Ehrlen, J. 2002. Assessing the lifetime consequences of plantanimal interactions for the perennial herb Lathyrus vernus (Fabaceae). Perspectives in Plant Ecology Evolution and Systematics 5:145-163.

Fritz, R., and E. Simms. 1992. Plant resistance to herbivores and pathogens: ecology, evolution and genetics. University of Chicago Press, Chicago, Illinois, USA.

Gaines, S. D. 1985. Herbivory and between-habitat diversitythe differential effectiveness of defenses in a marine plant. Ecology 66:473-485.

Gimenez, L. 2004. Marine community ecology: importance of trait-mediated effects propagating through complex life cycles. Marine Ecology Progress Series 283:303-310.

Ginsburg, D. W., and V. J. Paul. 2001. Chemical defenses in the sea hare Aplysia parvula: importance of diet and sequestration of algal secondary metabolites. Marine Ecology Progress Series 215:261-274.

Graham, L. E., and L. W. Wilcox. 2000. The origin of alternation of generations in land plants: a focus on matrotrophy and hexose transport. Philosophical Transactions of the Royal Society B 355:757-767.

Hay, M., and W. Fenical. 1988. Marine plant-herbivore interactions - the ecology of chemical defense. Annual Review of Ecology and Systematics 19:111-145.

Hay, M., J. J. Stachowicz, E. Cruz-Rivera, S. Bullard, M. Deal, and N. Lindquist. 1998. Bioassays with marine and freshwater organisms. Pages 39-141 in K. Haynes and J. Millar, editors. Methods in chemical ecology, volume 2. Chapman and Hall, Norwell, Massachusetts, USA.

Hughes, J. S., and S. P. Otto. 1999. Ecology and the evolution of biphasic life cycles. American Naturalist 154:306-320.

Jing, S.W., and P. D. Coley. 1990. Dioecy and herbivory - the effect of growth-rate on plant defense in Acer negundo. Oikos 58:369-377. 
Kamiya, M., and H. Kawai. 2002. Dependence of the carposporophyte on the maternal gametophyte in three ceramiacean algae (Rhodophyta), with respect to carposporophyte development, spore production, and germination success. Phycologia 41:107-115.

Kirkpatrick, M. E. 1994. The evolution of haploid-diploid life cycles. Lectures on Mathematics in the Life Sciences. American Mathematical Society, Providence, Rhode Island, USA.

Klinger, T. 1993. The persistence of haplodiploidy in algae. Trends in Ecology and Evolution 8:256-258.

Lockwood, J. R. 1998. On the statistical analysis of multiplechoice feeding preference experiments. Oecologia 116:475481.

Lubchenco, J., and J. Cubit. 1980. Heteromorphic life histories of certain marine algae as adaptations to variations in herbivory. Ecology 61:676-687.

Mable, B., and S. Otto. 1998. The evolution of life cycles with haploid and diploid phases. BioEssays 20:453-462.

Marquis, R. J., I. R. Diniz, and H. C. Morais. 2001. Patterns and correlates of interspecific variation in foliar insect herbivory and pathogen attack in Brazilian cerrado. Journal of Tropical Ecology 17:127-148.

Marshall, D. J., and M. J. Keough. 2006. Complex life cycles and offspring provisioning in marine invertebrates. Integrative and Comparative Biology 46:643-651.

Martinez, E. A., and B. Santelices. 1998. Selective mortality on haploid and diploid microscopic stages of Lessonia nigrescens Bory (Phaeophyta, Laminariales). Journal of Experimental Marine Biology and Ecology 229:219-239.

McConnell, O., and W. Fenical. 1977. Halogen chemistry of red alga Asparagopsis. Phytochemistry 16:367-374.

McKey, D. 1979. The distribution of secondary compounds within plants. Pages 55-133 in G. A. Rosenthal and D. H. Janzen, editors. Herbivores: their interactions with secondary plant metabolites. Academic Press, New York, New York, USA.

Paul, N. A., R. de Nys, and P. D. Steinberg. 2006a. Seaweedherbivore interactions at a small scale: direct tests of feeding deterrence by filamentous algae. Marine Ecology Progress Series 323:1-9.

Paul, N. A., R. de Nys, and P. D. Steinberg. 2006b. Chemical defence against bacteria in the red alga Asparagopsis armata: linking structure with function. Marine Ecology Progress Series 306:87-101.

Pavia, H., G. Toth, and P. Aberg. 1999. Trade-offs between phlorotannin production and annual growth in natural populations of the brown seaweed Ascophyllum nodosum. Journal of Ecology 87:761-771.
Pearse, I. S., T. Krugel, and I. T. Baldwin. 2006. Innovation in anti-herbivore defense systems during neopolypoloidy - the functional consequences of instantaneous speciation. Plant Journal 47:196-210.

Peterson, C. H., and P. E. Renaud. 1989. Analysis of feeding preference experiments. Oecologia 80:82-86.

Podolsky, R. D., and A. L. Moran. 2006. Integrating function across marine life cycles. Integrative and Comparative Biology 46:577-586.

Poore, A., and P. D. Steinberg. 1999. Preference-performance relationships and effects of host plant choice in an herbivorous marine amphipod. Ecological Monographs 69: 443-363.

Quinn, G., and M. J. Keough. 2002. Experimental design and data analysis for biologists. Cambridge University Press, Cambridge, UK.

Rhoades, D. F. 1979. Evolution of plant chemical defense against herbivores. Pages 3-54 in G. A. Rosenthal and D. H. Janzen, editors. Herbivores: their interactions with secondary plant metabolites. Academic Press, New York, New York, USA.

Rogers, C. N. 2000. The costs and benefits of acquired algal secondary metabolites to Aplysia parvula. Thesis. University of New South Wales, Sydney, Australia.

Rogers, C. N., R. de Nys, and P. D. Steinberg. 2003. Ecology of the sea hare Aplysia parvula (Opisthobranchia) in New South Wales, Australia. Molluscan Research 23:185-198.

Slocum, C. J. 1980. Differential susceptibility to grazers in two phases of an inter-tidal alga - advantages of heteromorphic generations. Journal of Experimental Marine Biology and Ecology 46:99-110.

Stearns, S. C. 1992. The evolution of life histories. Oxford University Press, Oxford, UK.

Steinberg, P. D. 1988. Effects of quantitative and qualitative variation in phenolic compounds on feeding in three species of marine invertebrate herbivores. Journal of Experimental Marine Biology and Ecology 120:221-237.

Thornber, C. S., and S. D. Gaines. 2004. Population demographics in species with biphasic life cycles. Ecology 85:1661-1674.

Thornber, C., J. J. Stachowicz, and S. Gaines. 2006. Tissue type matters: selective herbivory on different life history stages of an isomorphic alga. Ecology 87:2255-2263.

Zupan, J. R., and J. A. West. 1990. Photosynthetic responses to light and temperature of the heteromorphic marine alga Mastocarpus papillatus (Rhodophyta). Journal of Phycology 26:232-23. 